the current demand for primary products and gives details of international agreements which are in force. Eleven primary products, ranging from petrol and metals to tea and coffee, are discussed in detail in terms of the nature and importance of the product, countries of supply, importing areas and national production figures, and the state of the market. British, United States and Common Market policies for trade with the less developed countries are discussed with a mass of information on the trade of the countries concerned. The guide concludes with a résume of the work of the UNCTAD board and committees, and makes three proposals - a cocoa agreement, a scheme for tariff preferences for less developed countries and a scheme for supplementary financial measures, which could well be important talking points at the New Delhi meeting next month.

\section{No Change at Caltech?}

The annual report of the president of the California Institute of Technology for the academic year now past provides the usual detailed and absorbing account of the institute's recent achievements. Although, this year, Dr Lee DuBridge has much to say about the launching of the institute's public appeal for $\$ 85$ million, his account of events does less than justice to the questions increasingly being asked among the faculty at Pasadena and their contemporaries elsewhere-is the pursuit of excellence, or pre-eminence, as Dr DuBridge calls it, in conflict with the educational needs of the undergraduates, now almost outnumbered by the faculty?

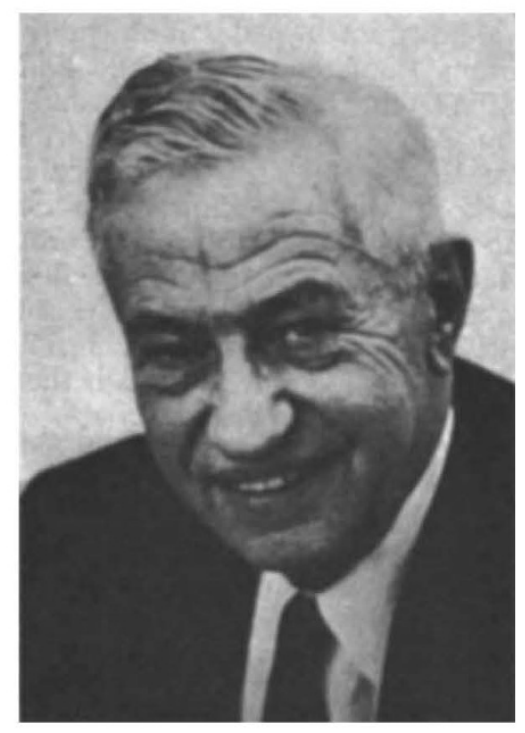

Dr Lee DuBridge, president cf the California Institute of Technology.

Like many other institutions, the California Institute of Technology is the continuing victim of what is now called sophistication. Simply staying still costs an extra 6 or 7 per cent a year. The institute wants to spend some of the $\$ 85$ million which it hopes to raise on new buildings, while some of it will be added to the endowment, which amounted to a comparatively modest $\$ 129$ million in 1967 . Within the running budget, which included expenditure of $\$ 30 \cdot 35$ million in 1967, federal research plays a prominent part. Thus the direct cost of federally sponsored research worked out at $\$ 11.22$ million, compared with $\$ 9.24$ for what is described as "instruction and research". In practice, the institute seems not too heavily dependent on any one agency for its funds-the US Navy provided $\$ 2 \cdot 13$ million and the US Air Force $\$ 1.74$ million in 1967, with roughly comparable amounts from the Public Health Service ( $\$ 3.21$ million), the AEC ( $\$ 2.69$ million), the NASA (\$2.17 million) and the NSF (\$2.01 million). It should fare as well as any other institution if, in the months ahead, there is a sharp reduction of the scale on which federal funds are made available. Whether the institute will be affected indirectly by the straitened NASA budget in the years ahead is another matter, for annual expenditure at the Jet Propulsion Laboratory which is managed on behalf of federal agencies by the institute grew by less than 1 per cent (to $\$ 248$ million) between 1966 and 1967 , and could conceivably decline in the years immediately ahead.

Financial considerations have not, however, impeded the sustained if modest growth of the institute in the recent past. The faculty, for example, has grown from 515 to 600 in five years, with the number of full professors almost unchanged at 142 but with a rapid increase from 159 to 206 in the number of research fellows. The intake of undergraduates, by contrast, has been constant for some years at 200 or so, but outsiders will be a little surprised that the rate of application for entry is only five times as great. Dropouts account for 39 per cent of the student body over a four year undergraduate course, though no doubt some of these people complete their undergraduate degrees elsewhere. No doubt the rate of dropping out will be taken merely as a proof that even the more rigorous processes of selection cannot be a cast-iron assurance of academic success. At Caltech, as the Swann Committee has found in Britain, however, academic success begets academic temperament. Thus the production of $\mathrm{PhD}$ degrees is running at about 100 a year, and has not yet been much affected by the increase of the graduate school from 660 to 770 in the past three years. In 1967, for example, 70 per cent of those graduating with $\mathrm{PhD}$ degrees found jobs at universities or at research institutions.

\section{Decline of Bone Strontium}

A continuing decline of the concentration of radioactive strontium in human bones in the British Isles is recorded in the most recent of the reports on the subject by the Medical Research Council (Assay of Strontium-90 in Human Bone, HMSO, 3s.). The results are based on analyses carried out separately by the UK Atomic Energy Authority and by a group based on Scottish hospitals. Bone samples were obtained from the vertebrae of individuals dying between July and December 1966, and the results obtained by the two groups are shown in the following table.

\begin{tabular}{lcccc} 
& \multicolumn{2}{c}{ UKATA } & \multicolumn{2}{c}{ Glasgow } \\
& 1965 & 1966 & 1965 & 1966 \\
& & & & \\
Newborn and stillborn & $2 \cdot 5$ & $2 \cdot 2$ & $3 \cdot 4$ & $2 \cdot 7$ \\
Under 5 years & $6 \cdot 7$ & $5 \cdot 1$ & $8 \cdot 2$ & $6 \cdot 5$ \\
$\quad$ (excluding newborn) & & & & \\
6-23 months & $9 \cdot 1$ & $6 \cdot 2$ & $11 \cdot 0$ & $8 \cdot 3$
\end{tabular}


This accords well with the measurements of the concentration of radioactive materials in the atmosphere and in rain which have now been published by the Health Physics and Medical Division of the AERE, Harwell. The report (HMSO, 7s.), which runs up to the middle of 1967 , shows that the average concentration of strontium-90 in rainwater had decreased by roughly 40 per cent between the first half of 1966 and the first half of 1967 . Because rainfall in 1967 was considerably less than in the previous year, the actual deposition of strontium-90 in the first half of 1967 was only 40 per cent of that deposited in the same period during the preceding year. By the end of 1966 , it seems as if the rate of deposition of fresh strontium-90 had become comparable with and smaller than the rate of disappearance of deposited strontium-90 by means of radioactive decay, so that "for the first time", the "cumulative deposition began to decrease with" time". The balance was reversed with the spring rains in 1967, but it is clear that an end is in sight to the accumulation of radioactivity in the soil.

\section{All Quiet on the Quiet Sun}

Lrke a great actress in later life, the organization of the International Years of the Quiet Sun is now well settled in the habit of making its final appearance. Formally, it is true, the great symposium at Imperial College last July marked the end of the period of co-ordinated or at least simultaneous observation. Now there has appeared the latest issue of IQSY Notes, the twentyfirst, which is full of valedictory statements and which also contains the announcement that this issue will be the last. The next step is the publication of the Annals of the IQSY, which is being managed by the Royal Society. There will be admiration and even gratitude for the firm promise that the first of the eight or nine volumes in this series will appear early this year, and that publication of the whole series - which will include a record of the symposium last Julyshould be complete by the end of 1969. With luck, it should be possible to avoid overlap between the productions of the IQSY and of Dr Herbert Freeman's Commission on Solar and Terrestrial Physics, now in the process of gestation.

Although the latest IQSY Notes has no great surprises, it does provide some information about the financing of international operations like these. It is notable that the total cost of administering the IQSY for a period of $5 \frac{1}{2}$ years amounted to merely $\$ 173,000$ - a sum which had to cover the maintenance of the secretariat in London, the publication of manuals and the organization of meetings. The publication of the Annals is reckoned to cost a further $\$ 60,000$. Most of the funds have been raised by voluntary contributions from the national committees of participating countries. The statement of the council goes out of its way to emphasize that "the payment of a contribution has never been a condition of adherence to the IQSY programme. Contributing and non-contributing committees have been treated exactly alike. . . . This was essential, since the prime objective of the scientific programme was to encourage the widest possible geographical participation in the programme. . . ." This decision was no doubt wise, for the list of contributors suggests that some participants have been rather slow in paying up. It is perhaps understandable that Taiwan and the Congo should not have paid after the first year or two. It is more surprising that Belgium, Finland, Israel, Rumania and Switzerland should not have contributed after a similar period. The Soviet Union had only paid two contributions out of six by October last year-a total of $\$ 10,000$. Difficulties about the convertibility of the rouble (and of the rupee) are known to have been a complication in this connexion. But the IQSY seems to have managed well enough and, even if its scientific programme was inescapably a somewhat undramatic business, the organization may well have been able to establish standards of good management among international organizations.

\section{More Medical Science}

A sMaLL reform in the organization of the British Medical Association seems likely to come about as a result of suggestions made by Dr Ronald Gibson, chairman of the council of the association. Dr Gibson has proposed that all the scientific and educational work done by the BMA should be brought under the umbrella of a central board. As well as the work of the present Committee on Medical Science, the board would provide for scientific and sociological work. But the hope expressed by Dr Gibson that the BMA could in this way "prove its right to be considered a forceful entity in the field of medical science" is hardly realistic. The proposal does not recommend any increase in the money which the BMA spends on research-last year it was $£ 60,000$ - but simply concentrates on the reform of the committee structure. Nor is the suggestion particularly new-a similar idea was put forward some years ago. Dr Gibson has suggested that if the board is set up-a decision which the council of the BMA will have to take within the next few weeks-it might also sponsor some general sociological surveys. Topics put forward include drug addiction, the population explosion, nutrition, the stress diseases and the like.

There seems to be no reason why the council should not approve the suggestion, modest as it is. It may, however, put the BMA into a position where it could begin to influence medical research in Britain, given a greater financial outlay. A counterweight to the massive influence of the Medical Research Council would not be entirely unwelcome. The field where the BMA might be most influential, clinical research, has not so far had the same attention in the MRC as more basic studies, although this may change when the MRC Clinical Research Centre opens at Brent Hospital in 1970. In the BMA, the move reflects a feeling that the politics of medicine has in the past few years been allowed to obscure the more cerebral activities of the BMA. Having exhibited its taste and talent for political controversy, the argument runs, the BMA should now try to divorce itself somewhat from the image of a militant, if successful, trade union.

The American Medical Association itself turned to research for many of the same reasons several years ago. There was a feeling that the AMA had become too closely identified with the fight against the Medicare proposals, and too far detached from scientific research. But the move to support basic research, in the Institute for Biomedical Research at the AMA headquarters in Chicago, seems not to have been wholly successful. After only two years of existence, the institute is now 